\title{
Effect of metformin on outcome in patients undergoing primary percutaneous coronary intervention for st-segment elevation myocardial infarction
}

\author{
RA Posma ${ }^{1 *}$, E Lipsic $^{2}$, P van der Harst ${ }^{2}$, I van der Horst ${ }^{1}$ \\ From ESICM LIVES 2015 \\ Berlin, Germany. 3-7 October 2015
}

\section{Introduction}

The oral antihyperglycemic agent metformin was associated with favorable outcome and smaller myocardial infarct size in patients with diabetes undergoing percutaneous coronary interventions (PCI) for ST-segment elevation myocardial infarction (STEMI) [1,2]. However, these findings have not been validated.

\section{Objectives}

To determine the effect of chronic metformin treatment on cardiovascular morbidity and mortality in patients with diabetes presenting with STEMI subsequently undergoing PCI.

\section{Methods}

From January 2004 until June 2013, all consecutive critically ill patients undergoing primary PCI for STEMI at the University Medical Center Groningen were included in a registry and 1-year follow-up was obtained. Our primary endpoint consisted of the composite endpoint of myocardial infarction, target vessel and target lesion revascularization, and all-cause mortality (MACE). The secondary endpoint, myocardial infarction size, was estimated using peak levels of creatine kinase (CK), the myocardial band of CK (CK-MB), troponin $\mathrm{T}$, and high-sensitive troponin $\mathrm{T}$ (hs-troponin T). The effect of metformin on myocardial infarct size from the 2004-2010 cohort has been reported previously [1]. Therefore myocardial infarction size was reported for patients admitted from 2011 until 2013 and the combined 2004-2013 cohort.

\section{Results}

In total, 4776 consecutive patients underwent primary PCI for STEMI, 719 (15\%) diabetic patients were included in the final analysis and $215(30 \%)$ patients used metformin at admission. MACE and mortality rates were $21 \%$ and $12 \%$ for patients with diabetes, $23 \%$ and $19 \%$ for metformin patients, $21 \%$ and $15 \%$ for patients on sulfonylurea, and $30 \%$ and $20 \%$ for patients on insulin, respectively. Metformin was not associated with reduced risk for MACE (adjusted hazard ratio (aHR): 1.19 (95\% confidence interval (95\%CI) 0.78-1.81), $\mathrm{P}=0.42$ ) or survival benefit (aHR: 0.23 (CI95\% 0.80$2.51), P=0.23)$ compared to diabetic patients not using metformin. Insulin use was an independent predictor for MACE (aHR 1.73 (CI95\% 1.13-2.65), P = 0.01) and all-cause mortality (aHR 1.81 (CI95\% 1.03-3.21), P = 0.04). Baseline levels of CK, CK-MB, and hs-troponin $T$ were comparable between both groups. Median (interquartile range) peak levels of $\mathrm{CK}, \mathrm{CK}-\mathrm{MB}$, and hs-Troponin $\mathrm{T}$ were all non-significant lower in the metformin group (table 1). When both cohorts were combined, peak levels of CK, CK-MB, and troponin $\mathrm{T}$ were all significantly lower in patients using metformin, as depicted in table 1.

\section{Conclusions}

Chronic metformin use in patients presenting with STEMI was associated with smaller infarct-size and not with lower MACE and mortality rates, as compared to other patients with diabetes. 
Table 1

\begin{tabular}{|c|c|c|c|c|c|c|}
\hline \multirow[b]{2}{*}{ Peak value } & \multicolumn{2}{|c|}{ 2011-2013 cohort } & \multicolumn{4}{|c|}{ Combined 2004-2013 cohort } \\
\hline & Metformin $(n=83)$ & No metformin $(n=72)$ & P-value & Metformin $(n=254)$ & No metformin $(n=537)$ & P-value \\
\hline CK (U/L) & $846(297-2317)$ & $1083(481-3005)$ & 0.25 & $1000(297-3594)$ & $1371(597-3034)$ & 0.01 \\
\hline CK-MB (U/L) & $112(52-211)$ & $120(60-309)$ & 0.33 & $138(52-256)$ & $174(74-310)$ & $<0.01$ \\
\hline Hs-Troponin T (ng/L) & $2175(592-5337)$ & $2076(912-5512)$ & 0.70 & & & \\
\hline Troponin T ( $\mu \mathrm{g} / \mathrm{L})$ & & & & $2.53(0.55-7.63)$ & $3.93(1.39-8.67)$ & 0.01 \\
\hline
\end{tabular}

\section{Authors' details}

'University Medical Center Groningen, Department of Critical Care, Groningen, Netherlands. ${ }^{2}$ University Medical Center Groningen, Department of Cardiology, Groningen, Netherlands.

Published: 1 October 2015

\section{References}

1. Lexis CPH, et al: Cardiovasc Drugs Ther 2014, 28:163-171.

2. Mellbin LG, et al: Eur Heart J 2008, 29:166-176.

doi:10.1186/2197-425X-3-S1-A802

Cite this article as: Posma et al:: Effect of metformin on outcome in patients undergoing primary percutaneous coronary intervention for stsegment elevation myocardial infarction. Intensive Care Medicine Experimental 2015 3(Suppl 1):A802.

\section{Submit your manuscript to a SpringerOpen ${ }^{\mathcal{O}}$ journal and benefit from:}

- Convenient online submission

- Rigorous peer review

- Immediate publication on acceptance

- Open access: articles freely available online

- High visibility within the field

- Retaining the copyright to your article 